\title{
The Impact of Celebrity Credibility on Consumer's Purchase Intention toward the Footwear Industry in Malaysia: The Mediating Effect of Attitude toward Advertisement
}

\author{
Zu Qian ONG, Derek Lai Teik ONG* \\ Sunway University Business School, Malaysia \\ dereko@sunway.edy.my*
}

\begin{abstract}
Practices of using celebrities as spokespeople for commercialized products are continuously favoured toward the effort of marketing and positioning. The popularity of celebrity advertising is founded upon advertiser's belief on message credibility by well-known personalities to achieve greater attention, recall and behavioural intention among consumers. The present study assesses the impact of celebrity credibility on the underlying purchase intention of Malaysian consumers toward the footwear industry, by exploring the mediating role of attitude toward advertisement between celebrity credibility and purchase intention. The influence of endorser's characteristics and cultures on consumer's behavioural intention is explained through the applications of the Theory of Identification (Kelman, 1961, 2006) and the Meaning Transfer Model (McCracken, 1989) in this study. Descriptive findings collected from 200 potential consumers have suggested attitude toward advertisement as the catalyst of endorser's identification, for cultivating dimensions of celebrity credibility (trustworthiness, expertise and attractiveness) into transactional intention. The phenomenon of integration approaches of single phenomenon, with two theoretical perspectives (Mayer \& Sparrowe, 2013) is demonstrated in this product marketplace.
\end{abstract}

Keywords: Celebrity Endorsement, Credibility, Attitude toward Advertisement, Purchase Intention, Footwear

\section{Introduction}

The footwear industry has been prevailing across the Asia Pacific region, with an average yearly consumption of $25.02 \%$ between 2008 and 2013 (Euromonitor International, 2014). Uniqueness in consumption patterns and product characteristics further placed celebrity credibility as a determinant for this industry. Successful business achievements place attitude toward advertisement and attitude toward brand as sequential stages between celebrity credibility and purchase intention (Chaiken, 1979; Muda, Musa, Mohamed \& Borhan, 2014; Ohanian, 1990; Schouten, 2008). Massive endorser, advertising and administrative expenses uncover attitude toward advertisement to precede purchase intention. Yet, the direct influence of celebrity endorsement is vaguely supported. Therefore, this study specifically investigates celebrity credibility by Ohanian (1990) as an advertising effort toward favourable behavioural intentions in the footwear industry.

\section{Literature Review}

Theory of Identification \& Meaning Transfer Model: Two main theories have acted as the foundation for the current study. First being the Theory of Identification by Kelman $(1961,2006)$ in discussing the process upon adopting of opinions from external social influence. This theory explains the direct relationship between attitude formations from past social experience, personal attributes and upbringings, following intended individual behaviours. Subsequent being the Meaning Transfer Model by McCracken (1989) which outlines the process of a common celebrity endorsement stages within the marketplace (culture $\rightarrow$ endorsement $\rightarrow$ consumption) with the adoption of endorsed products through acceptance of endorser's values. Yet, noted that both theories manage to explore the impact of celebrity credibility on consumer's purchase intention through the process of opinion adoptions and development behavioural intention. Explaining similar phenomenon, the Theory of Identification discusses the direct influence of external stimuli on attitudinal change that entail potential actions. The Meaning Transfer Model further strengthens the current phenomenon through determining the process of adoption, specifically in celebrity endorsement. Therefore, the integration approach of single phenomenon, two theoretical perspectives is anchored within the current study (Mayer \& Sparrowe, 2013). In view of the social context, the three social influence 
processes by Kelman $(1961,2006)$ are deemed essential determinants toward behavioural predictions (power for compliance, attractiveness for identification, credibility for compliance). Given the practical dimensions of celebrity credibility: trustworthiness, expertise and attractiveness; Ohanion (1990) operationalizes the concept in assessing the norm of celebrity endorsement, as adopted within this study.

Celebrity Credibility: Celebrity's Trustworthiness, Celebrity's Expertise, Celebrity's Attractiveness: Beaulieu (2001) defines source credibility as the ability of acceptance through delivered claims from a specific party. Diversified applications imply ambiguous operational dimensions for source credibility in view of advertising and promotion, including trustworthiness by Nan (2013) and expertise by Pornpitakpan (2003). Previous studies encounter endorser's credibility as a combination of trustworthiness, expertise and attractiveness (Ohanian, 1990; Bhatt, Jayswal \& Patel, 2013; Rossiter \& Smidts, 2012).The concept of source credibility is often argued in having the tendency to persuade (Nan, 2013). Greater persuasiveness demands higher credibility within sources. Credibility transferred toward celebrity-endorsed products forms consumer's attitude, further behavioural intention (Subhadip, Varsha \& Pragati, 2013). Thus, the effectiveness of source credibility toward behavioural intention should not be overlooked in the footwear industry, hypothesized that:-

$\mathrm{H}_{1}$ : Celebrity credibility has a positive impact on consumer's purchase intention of footwear in Malaysia

Trust toward dependable guidance is formed when the sender is believed to be truthful and reliable (Tsai, Chin \& Chen, 2010). Mentioned by Chong, Yang \& Wong (2003), the perceived trustworthiness of an individual is significantly dependent over the individual's level of knowledge and skills. Trustworthiness further possesses greater potential in driving attention toward opinion change (Tormala \& Clarkson, 2008). Additional findings prove that trusted opinions induce positive purchasing behaviours (Chong et al., 2003; Yoon, Kim \& Kim, 1998). Therefore, hypothesis is predetermined that:-

$\mathrm{H}_{1 \mathrm{a}}$ : Celebrity's trustworthiness has a positive impact on consumer's purchase intention of footwear in Malaysia

Source expertise indicates the degree of perception regarding a person's ability to generate valid affirmation (Pornpitakpan, 2004). This concept presents the perceived competency in making accurate statements. Findings from numerous studies present leveraged persuasiveness from greater expertise (McGuire, 1969; Stemthal, Dholakia \& Leavitt, 1978). With attitudinal change as an antecedent, the degree of congruency between the expertise of source and personal ideas of consumers deemed influential (Clark, Wegener, Habashi \& Evans, 2011). Likewise, expertise toward followership is attainable through greater congruency. Supported by Lafferty, Goldsmith \& Flynn (2005) in positive relationship between expertise, willing and intention to purchase, this study hypothesized that:-

$\mathrm{H}_{1 \mathrm{~b}}$ : Celebrity's expertise has a positive impact on consumer's purchase intention of footwear in Malaysia

The concept of physical attractiveness is based upon society's evaluation of credibility by virtue that attractive sources hold greater likability toward favourable attitude change and product assessments (Joseph, 1982). Mentioned by Mills \& Aronson (1965), attractiveness is able to raise concession, under the condition that the message delivered is intended on influencing others' opinions. Higher physical attractiveness tends to boost persuasiveness due to the distinguishable characteristics (social context, interpersonal skills) that perceived the source as competent (Chaiken, 1979). Nevertheless, alignment between physical appearance, endorsed product and marketing effort would present credibility in attractive personals (Guido, Peluso \& Moffa, 2011; Liu, Huang \& Jiang, 2007). Herewith, the hypothesis is reviewed that:-

$\mathrm{H}_{1 \mathrm{c}}$ : Celebrity's attractiveness has a positive impact on consumer's purchase intention of footwear in Malaysia

Attitude toward Advertisement as the Predictor: Attitude is a general and permanent assessment of objects, affairs, people and behaviours (Hoyer \& MacInnis, 1997).Attitude is consistent and acts as a basis to individual's willingness in behaving under a specific manner (Fishbein \& Ajzen, 1975). This shows potential toward reviewing consumer's behavioural intention. The concept of attitude has been vastly applied in marketing research since the 1960 (Sallam \& Wahid, 2012). Gresham \& Shrimp (1985) have proposed the independent impact of attitude toward brand and attitude toward advertisement on purchase intention. This study specifically investigates the direct influence of attitude toward advertisement on consumer's purchase intention. Mackenzie, Lutz \& Belch (1986) refers attitude toward advertisement as the tendency of reacting 
specifically to advertising stimulants under the conditions of exposure. The attitude toward advertisement is shown to have significant impact on brand choice (Biehal, Stephens \& Curlo, 1992). Positive consumer's brand selection is deemed the consequent of favourable attitude toward advertisement. Surpassing the indirect relationship through attitude toward brand, Goldsmith, Lafferty \& Newell (2000) suggests direct relationship is significant between attitude toward advertisement and purchase intention. Therefore, hypothesized in this study that:-

$\mathrm{H}_{2}$ : Attitude toward advertisement has a positive impact on consumer's purchase intention of footwear in Malaysia

Attitude toward Advertisement as the Mediator: Erdogan, Baker \& Tagg (2001) proposed that effective advertisement through celebrity endorsements possess positive impact on actual purchases and sales. Thus, indirect relationship between celebrity endorsement and potential behaviours within the marketplace is present through favourable advertising effect. Demonstrated by Wu, Linn, Fu \& Sukoco (2012), direct influential relationship is significant between perceived advertisement credibility and attitude toward advertisement, and attitude toward advertisement and intention for purchase. Further studies supports that purchase intention can be affected through effective advertising (Sallam \& Wahid, 2012). Supportive results through the direct relationship between attitude toward advertisement and purchase intention is also demonstrated by Goldsmith et al. (2000), as well as Khairullah \& Khairullah (1999), bypassing the intervention of brand effect. Extend upon Banwari's (1990) findings between perceptions and behavioural intention, the mediating role of attitude toward advertisement on the footwear product market is reviewed within the current study:-

$\mathrm{H}_{3}$ : Attitude toward advertisement mediates celebrity credibility to consumer's purchase intention of footwear in Malaysia

Attitude toward advertisement is integrated within the indirect effect of celebrity credibility and consumer's purchase intention. With purchase intention constructed through advertising appeal and advertising effect, celebrity endorsement has played central role as an effective advertising tool (Wang, Cheng \& Chu, 2012). Sales of endorsed products indicate direct effectiveness of celebrity-based advertisement (MacInnis, Rao \& Weiss, 2002). Celebrity credibility has played a crucial role in connecting goods and services to the potential customers in both publicity and promotions. As suggested by Ohanian (1991) on trustworthiness, consumer's purchase intention is an extended process, through far-fetch evaluation process. Therefore, this study presents the hypothesis that:-

$\mathrm{H}_{3 \mathrm{a}}$ : Attitude toward advertisement mediates celebrity's trustworthiness and consumer's purchase intention of footwear in Malaysia

However, Ohanian (1991) capitalizes on the direct relationship between expertise and purchase intention with vague influence from celebrity's trustworthiness and attractiveness. While celebrities' characteristics play a role in determining consumer's purchase intention, the embedment of the qualities upon advertisement effectiveness is accounted (Goldsmith et al., 2000; Lafferty \& Goldsmith, 1999; Lafferty et al., 2005).The mediating effect of attitude toward advertisement between celebrity's expertise and consumer's purchase intention is defined in this study. This entails the hypothesis that:-

$\mathrm{H}_{3 \mathrm{~b}}$ : Attitude toward advertisement mediates celebrity's expertise and consumer's purchase intention of footwear in Malaysia

Findings by Comiati \& Plăias (2010) suggested significant relationship between attractiveness consumer's reactions toward advertisement, based upon different circumstances that the celebrity endorsement approach is applied. Sallam (2011) further proposed the indirect relationship between the dimensions of celebrity credibility on purchase intention, through attitude toward advertisement and attitude toward brand. Therefore, this study accounts for attitude through advertising between celebrity's attractiveness and purchase intention. Hypothesis in this product market is determined that:-

$\mathrm{H}_{3 \mathrm{c}}$ : Attitude toward advertisement mediates celebrity's attractiveness and consumer's purchase intention of footwear in Malaysia

Based on reviews of the aforementioned past studies, this study proposes the conceptual framework as shown in Figure 1. 


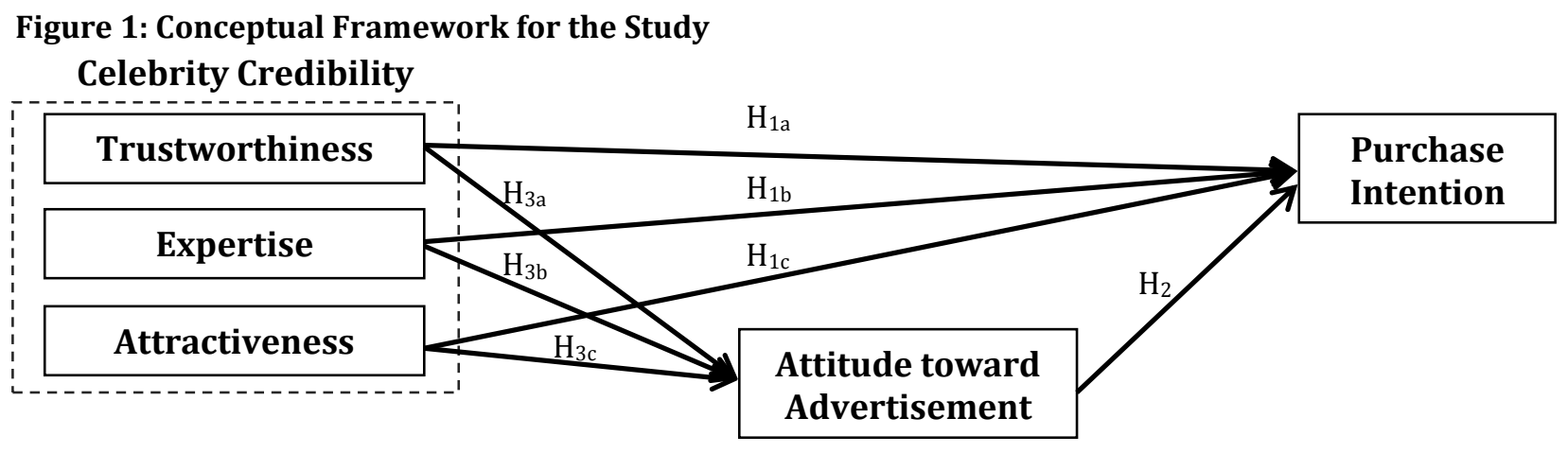

\section{Methodology}

This study is descriptive in nature as it seeks to examine the impact of celebrity credibility on purchase intention, through the formation of attitude toward advertisement in Malaysia's footwear industry. A quota sampling approach composed of even distribution of gender is adopted for the sake of convenience, efficiency and administrative effectiveness (Moser, 1952). Hinkin (1995) has recommended a question-to-sample ratio of 1 to 4 and 1 to 10 , which determines a minimum of 90 respondents at 23 questionnaire items (90 to 230). 200 respondents among undergraduate students are surveyed due to their homogeneity and suitability toward wider product classes for unbiased and reliable findings. Questionnaire survey method is used for the purpose of data collection in this study, as it allows the gauge of insightful information, including beliefs, viewpoints and assessments simultaneously (Aaker, Kumar, Day \& Leon, 2011). The questionnaire is consisted of five sections, namely celebrity's trustworthiness, celebrity's expertise, celebrity's attractiveness, attitude toward advertisement and consumer's purchase measured through 7-point Likert scale 1 = Strongly Disagree; 7 = Strongly Agree), as shown in Table 1. General open-ended questions and demographic information are included to assess respondent's opinions and backgrounds.

Table 1: Source of Instruments \& Cronbach's Alpha

\begin{tabular}{llll}
\hline Variable & Source & No. of Items & Chronbach's Alpha \\
\hline Celebrity's Trustworthiness & Choi \& Rifon,2012 & 5 & 0.901 \\
Celebrity's Expertise & Lafferty \& Goldsmith, 1999 & 5 & 0.922 \\
Celebrity's Attractiveness & Ohanian, 1990 & 5 & 0.928 \\
Attitude toward Advertisement & Sallam \& Wahid, 2012 & 5 & 0.898 \\
Purchase Intention & Janssens \& De Pelsmacker, 2005 & 3 & 0.855 \\
\hline
\end{tabular}

\section{Results \& Findings}

Findings from a bivariate correlation analysis suggest the existence of weak positive relationship between the elements of celebrity credibility and purchase intention, with Pearson's correlation ( $\mathrm{r}$ ) valued between 0.278 and 0.343 (significance level of $\mathrm{p}<0.01$ ). Attitude toward advertisement and purchase intention are shown to have a moderate positive relationship, with a Pearson's correlation (r) of 0.390 (significance level of $p<0.01$ ). An F-value of 35.519 is obtained from the multiple linear regression analysis for $\mathrm{H}_{1 \mathrm{a}}, \mathrm{H}_{1 \mathrm{~b}}, \mathrm{H}_{1 \mathrm{c}}$ and $\mathrm{H}_{2}$ at a significance level of 0.000 (significance level of $\mathrm{p}<0.01$ ), which indicates the presence of causal relationship between variables in this study. Given an R-squared value $\left(\mathrm{R}^{2}\right)$ of 0.152 , about $15.2 \%$ of the outcome variance is explained by the adopted construct. The findings suggest that celebrity's trustworthiness $(\mathrm{p}=0.378$, $\beta=0.720, t=0.883)$, celebrity's expertise $(p=0.960, \beta=0.137, B=, t=1.674)$ and celebrity's attractiveness $(\mathrm{p}=0.640, \beta=0.158, \mathrm{t}=1.860$ ) possess insignificant impact on purchase intention (significance level of $\mathrm{p}<$ 0.01). On the case of $\mathrm{H}_{2}$, attitude toward advertisement ( $\left.\mathrm{p}=0.000, \beta=0.390, t=5.960\right)$ is shown to possess significant impact on purchase intention (significance level of $p<0.01$ ). This constructs the regression equation as below. Figures in this study indicate that attitude toward advertisement being the sole direct predictor to purchase intention in this product market.

Purchase Întention (predicted) $=\mathrm{f}$ (Attitude toward Advertisement)

$\mathrm{PI}=3.273+0.390(\mathrm{Aad})$ 
Findings from multiple linear regression analysis for $\mathrm{H}_{3 a}$ indicate significant causal relationships for all total effect, direct effect and indirect effect as shown below (significance level of $p<0.01$ ). A conducted Sobel Test presents positive support with $\mathrm{z}=3.951, \mathrm{p}=0.000$ (significance level of $\mathrm{p}<0.01$ ). Attitude toward advertisement is determined to be a partial mediator on celebrity's trustworthiness and purchase intention.

Table 2: Coefficient of the Mediation Model $\left(\mathrm{H}_{3 \mathrm{a}}\right)$

\begin{tabular}{|c|c|c|c|c|c|c|c|c|c|c|c|c|c|c|}
\hline \multicolumn{5}{|c|}{ Total Effect $(\mathrm{CT} \rightarrow \mathrm{PI})$} & \multicolumn{5}{|c|}{ Direct Effect (CT, Aad $\rightarrow$ PI) } & \multicolumn{5}{|c|}{ Indirect Effect (CT $\rightarrow$ Aad) } \\
\hline $\begin{array}{l}\mathrm{B} \\
0.242\end{array}$ & $\begin{array}{l}\beta \\
0.278\end{array}$ & & & $\begin{array}{l}\mathrm{p} \\
0.000\end{array}$ & $\begin{array}{l}\mathrm{B} \\
0.348\end{array}$ & $\begin{array}{l}\beta \\
0.347\end{array}$ & & $\begin{array}{l}\mathrm{t} \\
4.275\end{array}$ & & $\begin{array}{l}\text { B } \\
0.515\end{array}$ & $\begin{array}{l}\beta \\
0.593\end{array}$ & & & $\begin{array}{l}\mathrm{p} \\
0.000\end{array}$ \\
\hline
\end{tabular}

Findings from multiple linear regression analysis for $\mathrm{H}_{3 \mathrm{~b}}$ indicate significant causal relationships for all total effect, direct effect and indirect effect as shown below (significance level of $p<0.01$ ). A conducted Sobel Test presents positive support with $\mathrm{z}=3.553, \mathrm{p}=0.000$ (significance level of $\mathrm{p}<0.01$ ). Attitude toward advertisement is determined to be a partial mediator on celebrity's expertise and purchase intention.

Table 3: Coefficient of the Mediation Model $\left(\mathrm{H}_{3 \mathrm{~b}}\right)$

\begin{tabular}{|c|c|c|c|c|c|c|c|c|c|c|c|c|c|c|}
\hline \multicolumn{5}{|c|}{ Total Effect (CE $\rightarrow$ PI) } & \multicolumn{5}{|c|}{ Direct Effect (CE, Aad $\rightarrow$ PI) } & \multicolumn{5}{|c|}{ Indirect Effect (CE $\rightarrow$ Aad) } \\
\hline $\begin{array}{l}\mathrm{B} \\
0265\end{array}$ & & SE & & & $\mathrm{B}$ & $\beta$ & & & & & & & & .000 \\
\hline
\end{tabular}

Findings from multiple linear regression analysis for $\mathrm{H}_{3 c}$ indicate significant causal relationships for all total effect, direct effect and indirect effect as shown below (significance level of $p<0.01$ ). A conducted Sobel Test presents positive support with $\mathrm{z}=3.277, \mathrm{p}=0.001$ (significance level of $\mathrm{p}<0.01$ ). Attitude toward advertisement is determined to be a partial mediator on celebrity's attractiveness and purchase intention.

Table 4: Coefficient of the Mediation Model $\left(\mathrm{H}_{3 c}\right)$

\begin{tabular}{|c|c|c|c|c|c|c|c|c|c|c|c|c|c|c|}
\hline \multicolumn{5}{|c|}{ Total Effect (CA $\rightarrow$ PI) } & \multicolumn{5}{|c|}{ Direct Effect (CA, Aad $\rightarrow$ PI) } & \multicolumn{5}{|c|}{ Indirect Effect (CA $\rightarrow$ Aad) } \\
\hline $\mathrm{B}$ & $\beta$ & $\mathrm{SE}$ & $\mathrm{t}$ & $\mathrm{p}$ & $\mathrm{B}$ & $\beta$ & $\mathrm{SE}$ & $\mathrm{t}$ & $\mathrm{p}$ & $\mathrm{B}$ & $\beta$ & SE & $\mathrm{t}$ & $\mathrm{p}$ \\
\hline 0.286 & 0.343 & 0.056 & 5.134 & 0.000 & 0.289 & 0.289 & 0.085 & 3.413 & 0.001 & 0.534 & 0.641 & 0.046 & 11.740 & 0.000 \\
\hline
\end{tabular}

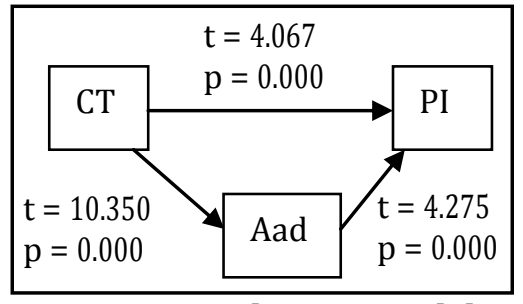

Figure 2: Mediation Model $\left(\mathrm{H}_{3 \mathbf{a}}\right)$

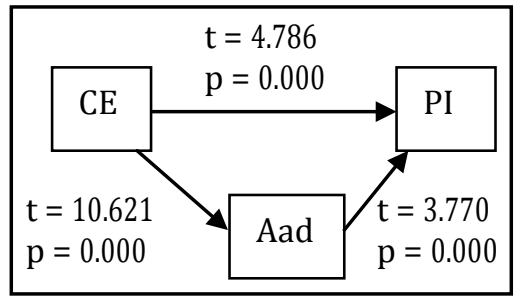

Figure 3: Mediation Model $\left(\mathbf{H}_{3 b}\right)$

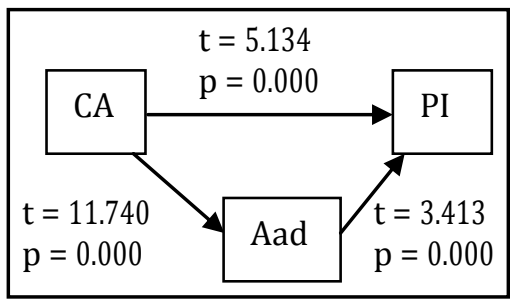

Figure 4: Mediation Model $\left(\mathrm{H}_{3 \mathrm{c}}\right)$

Discussions: This study extends upon Ohanian's (1990) assessments on celebrity credibility. The findings partially support Nan (2013) and Ohanian (1991) with insignificance of trustworthiness, expertise and attractiveness on consumer's intention to purchase. Potential impact of celebrity credibility presents insufficient direct behavioural significance. The findings rebut the phenomenon of previous studies which present direct influence of celebrity credibility on behavioural intention (Daneshvary \& Schwer, 2000; Ilicic \& Webster, 2011; Matthew, Huang \& Jiang, 2007; Morin, Ivory \& Tubbs, 2012; Tran, 2013; Wang et al., 2012). Van der Waldt, de Beer \& du Plessis (2007) supports a positive association between celebrity endorsement and likability toward endorsed products, consider high alignment between the marketing strategy and the endorsed products. Nevertheless, studies of similar concept places emphasis on the indirect influence of attitude toward brand, attitude toward advertisement, attitude toward appeal and product congruence (Yan, Ogle \& Hyllegard, 2010; Wang \& Lin, 2011; Choi \& Rifon, 2012). Thus, this study rebuts the direct causal relationship between celebrity credibility and purchase intention. 
The results further supports attitude toward advertisement as a predictor toward purchase intention (Goldsmith et al., 2000; Khairullah \& Khairullah, 1999; Sallam \& Wahid, 2012). Within the context of celebrity endorsement, study by Van der Waldt et al. (2007) has supported effective advertising as a significant predictor toward influencing purchase intention. Positive attitude toward advertisement is regarded alongside preferred product brands (Beihal, Stephens \& Curlo, 1992). Gresham \& Shrimp (1985) have also proposed the existence of causal relationship between attitude toward advertisement on attitude toward brand, with a peripheral statement regarding independent relationship of attitude toward advertisement and attitude toward brand on purchase intention. While the sequential effect of attitude toward advertisement and attitude toward brand is established, Goldsmith, Lafferty \& Newell (2000), Sallam \& Wahid (2012) and Yoon et al. (1998) have supported the causal effect of attitude toward advertisement on behavioural intention. In view of the study's focus, perceptions toward advertisement entail significant impact on positive behavioural intention.

Attitude toward advertisement is extended to the mediating role in this study, as supported by Banwari (1990) and Shrimp (1981). Indirect relationship between celebrity credibility and behavioural intention is constructed in this study, through attitude formed. Goldsmith et al. (2000), as well as Lafferty \& Goldsmith (1999) have also emphasized the sequential relationship under the influence of attitude toward advertisement within celebrity endorsement (celebrity credibility $\rightarrow$ attitude toward advertisement $\rightarrow$ purchase intention).In absent of direct relationship between celebrity credibility and purchase intention, Schouten (2008), Chaiken (1979) and Wu et al. (2012) have proposed positive attitude toward advertisement with high credibility of endorsers and advertisements. Choi \& Rifon (2012) further justified the causal relationship of attitude toward advertisement on purchase intention. Thus, attitude formed toward advertisement acts as a medium in the influence of celebrity credibility on purchase intention. Likewise, Muralidrahan \& Xue (2014) suggests the importance of marketplace conditions, advertised products, and celebrity's and viewer's attributes in determining advertising effectiveness on purchase intention.

Following the Theory of Identification, the study explores the implications of power, attractiveness and credibility on behavioural intentions and concept adoptions (Kelman, 1961, 2006). Access to external social stimuli further identifies the information in predicting consumer's potential behaviours (Lewisch, 2003). Extended by the Meaning Transfer Model (McCracken, 1989), the theory outlines the process of attitude formation and adoption with advertisement as the medium upon the influence of celebrity credibility, prior to behavioural intention. Meaning transfer influences the development of perceptions and evaluations on product brands, with alignment between endorsers and the endorsed products (Elina \& Leila, 2010; Miller \& Allen, 2012). Single situation in this study is explained through the application of both social science theories. This is outlined by Peak (2005) with celebrity characteristics alongside well-aligned advertising effort are key criteria toward potential consumptions. In congruence, the construct has justifies Mayer \& Sparrowe's (2013) rationale, with the integration approaches of single phenomenon, with two theoretical perspectives.

\section{Conclusion, Limitations \& Implications}

Reviews on the relationship between celebrity credibility and purchase intention recognize vague implication. Cultures and characteristics among celebrity endorsers exert substantial influence on consumerism within the footwear product market, yet, not directly. The sequential effect of celebrity credibility places high regards on developing positive attitude toward exposed advertising for underlying behavioural intention. Significant indirect effect of celebrity endorsers supports and extends meaning transfer between endorsers and consumers' potential purchases within this product market. Practicality of the findings acknowledges celebrity credibility as a factor to positive marketplace positioning through the process of attitude change, as to support the theoretical integration between cultural identification and meaning transfer. While limitations lie within the study's focused nature, exploring wider range of social communities and areas in future research would entail targeted implications. Noted, that individual uniqueness in perceptions regarding celebrity credibility may entail dissimilar intentions and behaviours. Therefore, potential congruency between endorser and product holds essentiality to effective marketing within the marketplace. 


\section{References}

Aaker, D. A., Kumar, V., Day, G. S. \& Leone, R. P. (2011). Marketing Research, $10^{\text {th }}$ edition, Asia: John Wiley \& Sons.

Banwari, M. (1990). The Relative Roles of Brand Beliefs and Attitude toward the Ad as Mediator of Brand Attitude: A Second Look. Journal of Marketing Research, 27(2), 209-219.

Beaulieu, P. (2001). The Effects of Judgments of New Clients' Integrity upon Risk Judgments, Audit Evidence, and Fees. Auditing: A Journal of Practice and Theory, 20(2), 85-99.

Bhatt, N., Jayswal, R. M. \& Patel, J. D. (2013). Impact of Celebrity Endorser's Source Credibility on Attitude towards Advertisements and Brands. South Asian Journal of Management, 20(4), 74-96.

Biehal, G., Stephens, D. \& Curlo, E. (1992). Attitude toward the Ad and Brand Choice. Journal of Advertising, 21(3), 19-36.

Chaiken, S. (1979). Communicator Physical Attractiveness and Persuasion. Journal of Personality and Social Psychology, 37(8), 1387-1397.

Choi, S. M. \& Rifon, N. J. (2012). It is a Match: The Impact of Congruence between Celebrity Image and Consumer Ideal Self on Endorsement Effectiveness. Psychology \& Marketing, 29(9), 639-650.

Chong, B., Yang, Z. \& Wong, M. (2003). Asymmetrical Impact of Trustworthiness Attributes on Trust, Perceived Value and Purchase Intention: A Conceptual Framework for Cross-cultural Study on Consumer Perception of Online Auction. Electronic commerce: Proceedings of the 5th international conference, 213-219.

Clark, J. K., Wegener, D. T., Habashi, M. M. \& Evans, A. T. (2011). Source Expertise and Persuasion: The Effects of Perceived Opposition or Support on Message Scrutiny. Personality and Social Psychology Bulletin, 38(1), 90-100.

Comiati, R. \& Plăias, I. (2010). The Impact of Endorsers' Characteristics on Consumers' Reaction to Ads. Management \& Marketing, 8(1), 37.

Daneshvary, R. \& Schwer, R. K. (2000). The Association Endorsement and Consumers' Intention to Purchase. Journal of Consumer Marketing, 17(3), 203-213.

Elina, H. K. \& Leila, H. (2010). Who Endorses Whom? Meanings Transfer in Celebrity Endorsement. Journal of Product \& Brand Management, 19(6), 452-460.

Erdogan, B. Z., Baker, M. J. \& Tagg, S. (2001). Selecting Celebrity Endorsers: The Practitioner's Perspective. Journal of Advertising Research, 41(3), 39-48.

Euromonitor International. (2014). Market Sizes (Footwear). Passport. Available from: http://www.portal.euromonitor.com.ezproxy.lancs.ac.uk/Portal/Pages/Statistics/Statistics.aspx [accessed: $22^{\text {th }}$ September 2014].

Fishbein, M. \& Ajzen, I. (1975). Belief, Attitude, Intention, and Behavior: An Introduction to Theory and Research, USA: Wesley Publishing Company.

Goldsmith, R. E., Lafferty, B. A. \& Newell, S. J. (2000). The Impact of Corporate Credibility and Celebrity Credibility on Consumer Reaction to Advertisements and Brands. Journal of Advertising, 29(3), 43-54.

Gresham, L. G. \& Shimp, T. A. (1985). Attitude toward the Advertisement and Brand Attitude: A Classical Conditioning Perspective. Journal of Advertising, 14(1), 10-49.

Guido, G., Peluso, A. M. \& Moffa, V. (2011). Beardedness in Advertising: Effects on Endorsers' Credibility and Purchase Intention. Journal of Marketing Communications, 17(1), 37-49.

Hinkin, T. R. (1995). A Review of Scale Development Practices in the Study of Organizations. Journal of Management, 21(5), 967-988.

Hoyer, W. T. \& MacInnis, D. (1997). Consumer Behaviour, Boston, MA: Houghton Mifflin.

Ilicic, J. \& Webster, C. M. (2011). Effects of Multiple Endorsements and Consumer-celebrity Attachment on Attitude and Purchase Intention. Australasian Marketing Journal, 19(4), 230-237.

Janssens, W. \& De Pelsmacker, P. (2005). Advertising for New and Existing Brands: The Impact of Media Context and Type of Advertisement. Journal of Marketing Communications, 11(2), 113-128.

Joseph, W. B. (1982). The Credibility of Physically Attractive Communicators: A Review. Journal of Advertising, 11(3), 15-24.

Kelman, H. C. (2006). Interests, Relationships, Identities: Three Central Issues for Individuals and Groups in Negotiating Their Social Environment. Peer Reviewed Journal, 57, 1-26.

Kelman, H. C. (1961). Processes of Opinion Change. Public Opinion Quarterly, 25, 57-78. 
Khairullah, D. Z. \& Khairullah, Z. Y. (1999). Relationships between Acculturation, Attitude toward the Advertisement, and Purchase Intention of Asian-Indian Immigrants. International Journal of Commerce \& Management, 9(3/4), 46-65.

Lafferty, B. A., Goldsmith, R. E. \& Flynn, L. R. (2005). Are Innovators Influenced by Endorser Expertise in an Advertisement when Evaluating a High Technology Product? Journal of Marketing Theory and Practice, 13(3), 32-48.

Lafferty, B. A. \& Goldsmith, R. E. (1999). Corporate Credibility's Role in Consumers' Attitudes and Purchase Intentions When a High versus a Low Credibility Endorser Is Used in the Ad. Journal of Business Research, 44(2), 109-116.

Lewisch, P. (2003). A Theory of Identification. International Review of Law and Economics, 23(4), 439-451.

Liu, M. T., Huang, Y. Y. \& Jiang, M. (2007). Relations among Attractiveness of Endorsers, Match-up, and Purchase Intention in Sport Marketing in China. The Journal of Consumer Marketing, 24(6), 358-365.

MacInnis, D. J., Rao, A. G. \& Weiss, A. M. (2002) Assessing when Increased Media Weight of Real World Advertisements Helps Sales. Journal of Marketing Research, 39(11), 391-407.

Mackenzie, S. B., Lutz, R. J. \& Belch, G. E. (1986). The Role of Attitude toward the Ad as a Mediator of Advertising Effectiveness: A Test of Competing Explanations. Journal of Marketing Research, 23(2), 130-143.

Matthew, T. L., Huang, Y. Y. \& Jiang, M. (2007). Relations among Attractiveness of Endorsers, Match-up, and Purchase Intention in Sport Marketing in China. The Journal of Consumer Marketing, 24(6), 358-365.

Mayer, K. J. \& Sparrowe, R. T. (2013). From the Editors: Integrating Theories in AMJ Articles. Academy of Management Journal, 56(4), 917-922.

McCracken, G. (1989). Who is the Celebrity Endorser? Cultural Foundation of the Endorsement Process. Journal of Consumer Research, 16(3), 310-321.

McGuire, W. J. (1969). The Nature of Attitudes and Attitude Change. In Lindzey, G. and Aronson, E. (Eds.). Handbook of Social Psychology, $2^{\text {nd }}$ edition (pp.135-214). Cambridge, MA: Addison-Wesley.

Miller, F. M. \& Allen, C. T. (2012). How does Celebrity Meaning Transfer? Investigating the Process of Meaning Transfer with Celebrity Affiliates and Mature Brands. Journal of Consumer Psychology, 22(3), 443-452.

Mills, J. \& Aronson, E. (1965). Opinion Change as the Function of Attractiveness and Desire to Influence. Journal of Personality and Social Psychology, 1(2), 173-177.

Morin, D. T., Ivory, J. D. \& Tubbs, M. (2012). Celebrity and Politics: Effects of Endorser Credibility and Sex on Voter Attitudes, Perceptions and Behaviors. The Social Science Journal, 49(4), 413-420.

Moser, C. A. (1952). Quota Sampling. Journal of Royal Statistical Society, 115(3), 411-423.

Muda, M., Musa, R., Mohamed, R. N. \& Borhan, H. (2014). Celebrity Entrepreneur Endorsement and Advertising Effectiveness. Procedia - Social and Behavioural Sciences, 130, 11-20.

Muralidharan, S. \& Xue, F. (2014). Influence of TV Endorser Types on Advertising Attitudes and Purchase Intention among Indian Rural Women: An Exploratory Study. Asian Journal of Communication, 25(2), 213-231.

Nan, X. (2013). Perceived Source Credibility and Advertising Persuasiveness: An Investigation of Moderators and Psychological Processes. Journal of Current Issues \& Research in Advertising, 34(2), 195-211.

Ohanian, R. (1990). Construction and Validation of a Scale to Measure Celebrity Endorsers' Perceived Expertise, Trustworthiness, and Attractiveness. Journal of Advertising, 19(3), 39-52.

Ohanian, R. (1991). The Impact of Celebrity Spokespersons' Perceived Image on Consumers' Intention to Purchase. Journal of Advertising Research, 31(1), 46-54.

Pornpitakpan, C. (2003). Validation of the Celebrity Endorsers' Credibility Scale: Evidence from Asians. Journal of Marketing Management, 19(1), 179-195.

Pornpitakpan, C. (2004). The Persuasiveness of Source Credibility: A Critical Review of Five Decades' Evidence. Journal of Applied Social Psychology, 34(2), 243-281.

Rossiter, J. R. \& Smidts, A. (2012). Print Advertising: Celebrity Presenters. Journal of Business Research, 65(6), 874-879.

Sallam, M. A. A. (2011). The Impact of Source Credibility on Saudi Consumer's Attitude toward Print Advertisement: The Moderating Role of Brand Familiarity. International Journal of Marketing Studies, 3(4), 63-77.

Sallam, M. A. A. \& Wahid, N. A. (2012). Endorser Credibility Effects on Yemeni Male Consumer's Attitudes towards Advertising, Brand Attitude and Purchase Intention: The Mediating Role of Attitude toward Brand. International Business Research, 5(4), 55-66. 
Schouten, B. C. (2008). Compliance Behavior and the Role of Ethnic Background, Source Expertise, Selfconstruals and Values. International Journal of Intercultural Relations, 32(6), 515-523.

Shrimp, T. A. (1981). Attitude toward the Ad as a Mediator of Consumer Brand Choice. Journal of Advertising, $10(2), 9-48$.

Stemthal, B., Dholakia, R. R. \& Leavitt, C. (1978). The Persuasive Effect of Source Credibility: Tests of Cognitive Response. Journal of Consumer Research, 4(4), 252-260.

Subhadip, R., Varsha, J. \& Pragati, R. (2013). The Moderating Role of Consumer Personality and Source Credibility in Celebrity Endorsements. Asia-Pacific Journal of Business Administrations, 5(1), 72-88.

Tormala, Z. L. \& Clarkson, J. J. (2008). Source Trustworthiness and Information Processing in Multiple Message Situations: A Contextual Analysis. Social Cognition, 26(3), 357-367.

Tran, G. N. (2013). The Role of Celebrity Endorsers. Society for Marketing Advances Proceedings, 25, 156-159.

Tsai, M. T., Chin, C. W. \& Chen, C. C. (2010). The Effect of Trust Belief and Salesperson' Expertise on Consumer's Intention to Purchase Nutraceuticals: Applying the Theory of Reasoned Action. Social Behavior \& Personality: An International Journal, 38(2), 273-288.

Van der Waldt, D. L. R., de Beer, N. \& du Plessis, N. (2007). Attitudes towards Attractive and Credible Celebrities in Advertisements: A Survey amongst Students. Communicare, 26(1), 44-58.

Wang, A. \& Lin, C. (2011). Effects of Content Class with Endorsement and Information Relevancy on Purchase Intention. Management Research Review, 34(4), 417-435.

Wang, J. S., Cheng, Y. F. \& Chu, Y. L. (2012). Effect of Celebrity Endorsements on Consumer Purchase Intentions: Advertising Effect and Advertising Appeal as Mediators. Human Factors and Ergonomics in Manufacturing \& Service Industries, 23(5), 357-363.

Wu, W. Y., Linn, C. T., Fu, C. S. \& Sukoco, B. M. (2012). The Role of Endorsers, Framing, and Rewards on the Effectiveness of Dietary Supplement Advertisements. Journal of Health Communication, 17, 54-75.

Yan, R. N., Ogle, J. P. \& Hyllegard, K. H. (2010). The Impact of Message Appeal and Message Source on Gen Y Consumers' Attitudes and Purchase Intentions toward American Apparel. Journal of Marketing Communications, 16(4), 203-224.

Yoon, K., Kim, C. H. \& Kim, M. S. (1998). A Cross-cultural Comparison of the Effects of Source Credibility on Attitudes and Behavioral Intentions. Mass Communication \& Society, 1(3/4), 153-173. 